\title{
Rebamipide, a novel antiulcer agent, attenuates Helicobacter pylori induced gastric mucosal cell injury associated with neutrophil derived oxidants
}

\author{
M Suzuki, S Miura, M Mori, A Kai, H Suzuki, D Fukumura, M Suematsu, $M$ Tsuchiya
}

\begin{abstract}
The effect of rebamipide, a novel antiulcer compound, on Helicobacter pylori activated neutrophil dependent in vitro gastric epithelial cell injury was investigated. Luminol dependent chemiluminescence (ChL), which detects toxic oxidants from neutrophils exhibited a 12-fold increase when the bacterial suspension of $H$ pylori was added to the isolated human neutrophils. This change was significantly attenuated by rebamipide at a concentration less than $1 \mathrm{mM}$, showing that rebamipide may inhibit oxidant production from $H$ pylori elicited neutrophils. To assess whether rebamipide attenuates gastric mucosal injury, we tested its inhibitory action on $H$ pylori induced gastric mucosal damage associated with neutrophils in vitro. Rabbit gastric mucosal cells were monolayered in culture wells and coincubated with human neutrophils and $\boldsymbol{H}$ pylori, and the cytotoxicity index was then calculated. Cultured gastric cells were significantly damaged when they were incubated with human neutrophils activated by $H$ pylori. This cellular damage was attenuated by rebamipide in a dose dependent manner. Furthermore, spectrophotometrical measurement showed that rebamipide (1 $\mathrm{mM}$ ) inhibits urease activity by $21 \cdot 7 \%$. As monochloramine (an oxidant yielded by reaction of neutrophil derived chlorinated oxidant and ammonia) is proposed as an important toxic molecule in this model, the current findings suggest that the preventive effect of rebamipide on $H$ pylori elicited neutrophil induced gastric mucosal injury may result from its inhibitory actions on the neutrophilic oxidative burst as well as $\mathrm{H}$ pylori derived urease activity.
\end{abstract} important pathogen of gastric disorder includmechanisms, however, by which $H$ pylori obscure. Antibiotics have been, therefore, only mucosal cell injury is reactive oxidants, which are released from activated neutrophils. Several studies have already shown that $H$ pylori itself exhibits chemotactic activity for neutrophils. ${ }^{1-5}$ We have also reported that $H$ pylori elicited neutrophils produce toxic oxidants, which subsequently injure cultured gastric mucosal cells, and that ammonia, which is derived from urea by $H$ pylori associated urease enhances the mucosal cytotoxicity, which may be regulated by monochloramine. ${ }^{67}$ Considering these mechanisms, the agents that can inhibit either neutrophil activation or ammonia production are proposed to be effective for $H$ pylori induced gastric mucosal injury. Rebamipide had been reported to promote mucus synthesis, ${ }^{8}$ mucosal prostaglandin content, and rapid ulcer healing. ${ }^{9}$ Moreover, it has recently been reported to inhibit the production of oxygen derived free radicals from stimulated neutrophils. ${ }^{10}$ In this report, we have evaluated whether rebamipide may influence active oxidant production elicited by $H$ pylori activated neutrophils and urease activity, and whether it attenuates gastric mucosal cell damage associated with $H$ pylori activated neutrophils in vitro.

\section{Methods}

CHEMICALS

The fluorochrome dye 2',7'-bis(2-carboxyethyl)-5(6)-carboxyfluorescein acetoxymethylester (BCECF-AM) was purchased from Molecular Probes (Eugene, OR). Urea was obtained from Sigma Chemicals (St Louis, MO). BCECF-AM solution was prepared in dimethyl sulphoxide (DMSO) at $1 \mathrm{mM}$. Rebamipide, ( \pm )-2-(4-chlorobenzoylamino)$3[2(1 \mathrm{H})$-quinolinon-4-yl] propionic acid (Otsuka Pharm Co, Japan) was dissolved in DMSO and was then diluted in phosphate buffered saline (PBS) before experiments. The final concentration of DMSO in each assay was adjusted at 3\%. Crystalline urease (Jack beans) was obtained from Sigma.

\section{MICROBIOLOGY}

H pylori, strain NCTC1 1637 (RPH13487) was a generous gift from Dr B J Marshall, Royal Perth Hospital, Australia. The bacteria was inoculated on sheep blood agar plate (Becton Dickinson Microbiology Systems,
(Gut 1994; 35: 1375-1378)

Helicobacter pylori has been shown to be an ing gastritis and gastric ulcer. The pathogenic causes the gastric mucosal damage still remain recently been used for $H$ pylori positive patients for the purpose of bacterial eradication. One of the potential toxic factors involving gastric

Department of
Internal Medicine,
School of Medicine,
Keio University, and
Tokyo Metropolitan
Research Laboratory
of Public Health,
Tokyo, Japan
M Suzuki
S Miura
M Mori
A Kai
H Suzuki
D Fukumura
M Suematsu
M Tsuchiya
Correspondence to:
Dr M Suzuki, Department of
Internal Medicine, School of
Medicine, Keio University,
35 Shinanomachi,
Shinjukuku, Tokyo 160,
Japan.
Accepted for publication
9 February 1994


Cockeysville, MD) at $37^{\circ} \mathrm{C}$ under microaerophilic conditions using an anaerobic chamber (Gaspak, Becton Dickinson Microbiology Systems). The bacteria was harvested and then washed with PBS ( $\mathrm{pH} \mathrm{7 \cdot 4)}$ for experiments.

\section{NEUTROPHILS}

Neutrophils were isolated from the human peripheral blood of one healthy volunteer with the use of standard dextran sedimentation and gradient separation on Histopaque 1077 (Sigma). This procedure yields a neutrophil population that is $95 \%$ viable (trypan blue exclusion) and 98\% pure (acetic acid crystal violet staining).

\section{CHEMILUMINESCENCE ASSAY}

The release of active oxidants from neutrophils stimulated by $H$ pylori was determined using a luminol dependent chemiluminescence ( $\mathrm{ChL}$ ) using the modified method as previously reported. ${ }^{7}$ Briefly, one millilitre of Dulbecco's modified Eagle's medium containing neutrophils $\left(1.5 \times 10^{6}\right)$ and $H$ pylori $\left(1.5 \times 10^{7}\right)$ was incubated with $20 \mu \mathrm{g}$ luminol for 60 minutes. The ChL counts were continuously recorded using a computer assisted 6-channel $\mathrm{ChL}$ analyser (Biolumat LB9505, Berthold, FRG). Integrated $\mathrm{ChL}$ counts (0-60 min) were used for the assessment.

\section{CYTOTOXICITY ASSAY}

The cytotoxicity measurement of cultured gastric mucosal cells was performed according to the previously reported method. ${ }^{6}$ Briefly, the stomachs of rabbit fetuses were separated and cultured. The cells were finally monolayered in a 48 -well tissue culture plate at $37^{\circ} \mathrm{C}$ in $5 \%$ carbon dioxide atmosphere. Histochemical analysis was performed by conventional staining with haematoxylin and eosin, periodic acid Schiff (PAS), and alkaline phosphatase. These methods showed that $>70 \%$ of the cells were identified as mucus producing epithelial cells by PAS staining. No alkaline phosphatase activity was detected, suggesting that the cultures were free of vascular endothelial cells. The monolayered mucous cells were labelled with BCECF-AM $(5 \mu \mathrm{M})$ for 20 minutes then incubated with modified Eagle's medium $(0.5 \mathrm{ml})$ containing $2 \mathrm{mM}$ urea, neutrophils $\left(7.5 \times 10^{5}\right)$, and $H$ pylori $\left(7 \cdot 5 \times 10^{6}\right)$ for two hours at $37^{\circ} \mathrm{C}$. For BCECF measurements, supernatants were harvested and centrifuged to remove floating leucocytes and bacteria. The supernatant was assayed for fluorescence intensity $\left(\mathrm{F}_{\text {super }}\right)$. The cells in each well were lysed by $0.5 \%$ Triton $\mathrm{X} 100$ to measure the fluorescence of targets $\left(F_{\text {lysate }}\right)$. The spontaneous release $\left(F_{\text {spont }}\right)$ was determined by incubating targets with medium alone. The samples were diluted in bicarbonate buffer ( $\mathrm{pH} \mathrm{9)}$ and then the fluorescence intensity was measured using a fluorescence spectrophotometer (F-3000, Hitachi). The excitation and emission wavelength was set at
$490 \mathrm{~nm}$ and $510 \mathrm{~nm}$, respectively. The specific $\%$ cytotoxicity was calculated from the equation:

$$
\text { Specific \% cytotoxicity }=\frac{F_{\text {super }}-F_{\text {spont }}}{F_{\text {super }}+F_{\text {lysate }}-F_{\text {spont }}} \times 100
$$

\section{UREASE ACTIVITY MEASUREMENT}

The inhibitory action of rebamipide on urease activity was determined spectrophotometrically. A mixture of $10 \mu l$ of rebamipide solution was combined with $10 \mu$ of 1.07 $\mathrm{mg} / \mathrm{ml}$ of urea then preincubated for 10 minutes at $37^{\circ} \mathrm{C}$. Thereafter, one $\mathrm{ml}$ of phosphate buffer $(90 \mathrm{mM}, \mathrm{pH} 7 \cdot 0)$ containing $0.1 \mathrm{U} / \mathrm{ml}$ urease, $0.25 \mathrm{M}$ sodium salicylate, and $6.7 \mathrm{mM}$ sodium nitrosylpentacyanoferrate (III) dihydrate was added and incubated for 15 minutes at $37^{\circ} \mathrm{C}$. The reaction was completed by adding one $\mathrm{ml}$ chromogen reagent (sodium hypochlorite and $\mathrm{NaOH}$ ), and then the absorbance was measured with a spectrophotometer (UNIDEC, Model 340, Japan) at $570 \mathrm{~nm}$. The inhibition percentage was calculated for the assessment.

\section{BACTERIAL GROWTH INHIBITION TEST}

The influence of rebamipide on $H$ pylori growth was determined by the agar dilution method. The bacterial suspensions $(n=5)$ were applied to the brucella blood agar plates containing rebamipide $(0 \cdot 1,0 \cdot 5$, and $1 \mathrm{mM})$. The plates were incubated at $37^{\circ} \mathrm{C}$ in a microaerobic environment. Readings were performed after three days of incubation.

\section{STATISTICAL ANALYSIS}

The statistical differences were determined by one way analysis of variance (ANOVA) and Dunnett type multiple comparison. All values are expressed as mean (SEM), and statistical significance was set at $\mathrm{p}<0.05$.

\section{Results}

CHEMILUMINESCENCE ASSAY (Fig 1)

The ChL value of resting neutrophils (neutrophils only, 3\% DMSO included) was 0.42 $(0.34)\left(\times 10^{8}\right.$ counts, $\left.\mathrm{n}=6\right)$ while it increased 12-fold after adding $H$ pylori (5.10 (1.49), $\mathrm{n}=5, \mathrm{p}<0.01)$. This is attenuated by rebamipide at concentrations of $0.1 \mathrm{mM}$ and $0.5 \mathrm{mM}(3.60(1.29), 1.75(0.63), \mathrm{n}=6)$ while $1 \mathrm{mM}$ rebamipide significantly decreased the ChL value $(1.01(0.38), n=6, p<0.05)$. These results show that rebamipide attenuates the release of active oxidants from $H$ pylori elicited neutrophils in a dose dependent manner.

\section{CYTOTOXICITY ASSAY (Fig 2)}

$H$ pylori activated neutrophils significantly increased specific \% cytotoxicity of cultured gastric mucosal cells to $33.9(4.89)(n=6$, $\mathrm{p}<0.01)$ compared with the control value $(-0.08(2.41), n=4)$. This damage was 


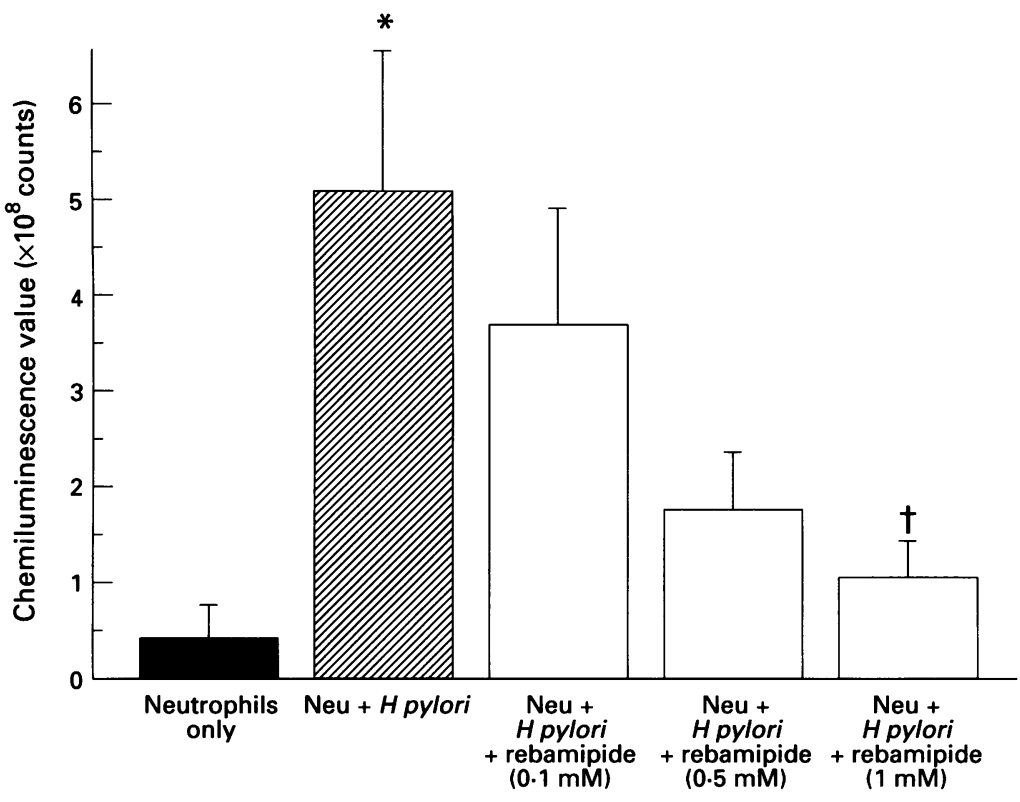

Figure 1: Luminol dependent chemiluminescence of human neutrophils. The application of bacterial suspension of $\mathrm{H}$ pylori to neutrophils causes a 12-fold increase of the ChL value, indicating the release of neutrophil derived oxidants. Pretreatment of rebamipide significantly attenuated this enhanced ChL value. Bars express standard error. ${ }^{\star} p<0.01$, compared with neutrophils only value. $t_{p}<0.05$, compared with neutrophils (Neu) $+\mathrm{H}$ pylori value. ammonia production by its inhibitory action on urease.

BACTERIAL GROWTH TEST

The growth of $H$ pylori was not inhibited by rebamipide at concentrations less than $1 \mathrm{mM}$. This result suggests that rebamipide may not have any influence on bacterial viability at a concentration of less than $1 \mathrm{mM}$.

\section{Discussion}

Eradication treatment using antibiotics has been generally approved for the treatment of patients with $H$ pylori positive gastritis and gastric ulcer. Few therapeutic strategies, however, which can abolish the cytotoxic action of $H$ pylori have been described. Among $H$ pylori associated cytotoxic factors, chemotaxin, which is detectable in $H$ pylori and its culture filtrate is one of the potential determinants of virulence because a significant neutrophil infiltration is characterised in $H$ pylori positive gastric mucosa. ${ }^{11} 12$ Yoshida et al have reported that this active factor elicits the upregulation of leucocyte adhesion molecules causing neutrophil adherence to venular endothelium in rat mesentery and to monolayers of human umbilical vein endothelial cells. ${ }^{13}$ Kurose et al have also seen that the mesenteric microvascular permeability is dramatically increased by $H$ pylori extract, which is neutrophil mediated. ${ }^{14}$ We have recently reported that $H$ pylori elicits chlorinated toxic oxidant production from neutrophils and that these substances play a critical part in $H$ pylori associated gastric mucosal damage. ${ }^{6} 7$

Rebamipide is a quinolinon derivative and Urease activity was significantly inhibited by rebamipide. Rebamipide $(0 \cdot 1 \mathrm{mM})$ suppressed enzyme activity by $6.4 \%$ while it was further inhibited by doses of 0.5 and $1 \mathrm{mM}(14.9 \%$ and $21 \cdot 7 \%$ ). These data suggest that rebamipide suppresses $H$ pylori mediated

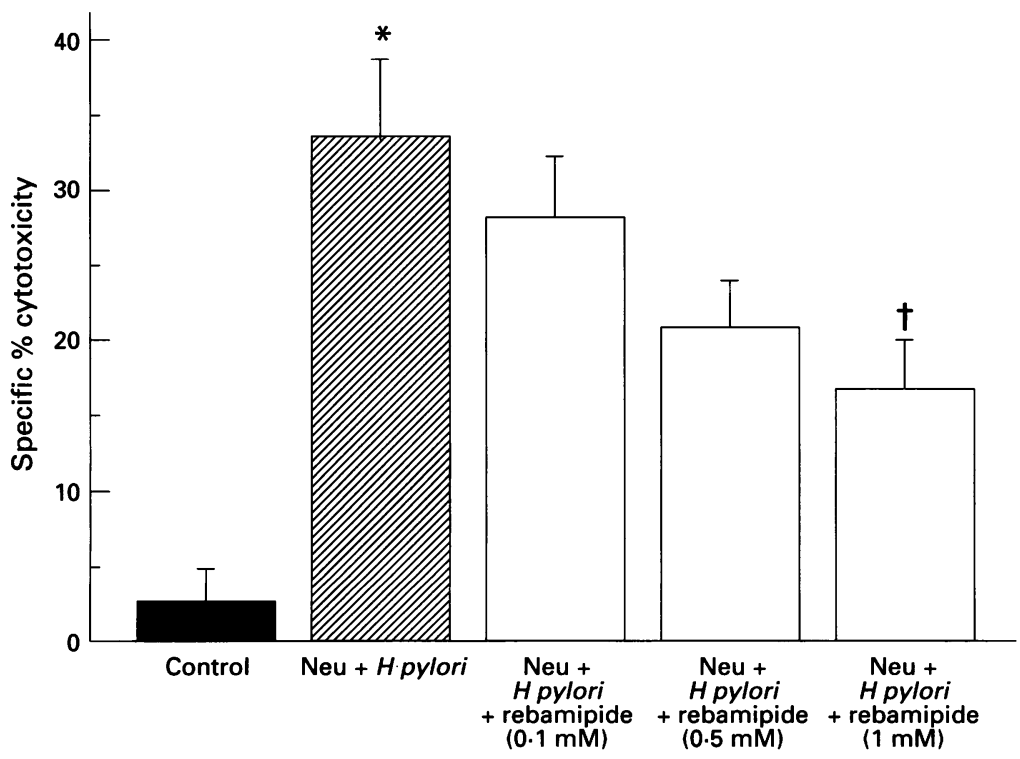

Figure 2: Gastric mucosal cell damage induced by $\mathrm{H}$ pylori activated neutrophils and the effect of rebamipide. The treatment with rebamipide significantly attenuated gastric mucosal injury induced by $\mathrm{H}$ pylori elicited neutrophils. Bars express standard error. ${ }^{\star} p<0 \cdot 01$, compared with control (modified Eagle's medium only) value. $\nmid p<0.05$, compared with neutrophils $+\mathrm{H}$ pylori value. its molecular weight is $370 \cdot 79$. This compound has been reported to possess antiulcer properties against ethanol or acid induced gastric mucosal damage. These effects have been interpreted by its pharmacological action on prostaglandin synthesis in gastric epithelium. ${ }^{9}$ The local concentration of rebamipide has not been reported in the human stomach while its mucosal concentration is more than $0.2 \mathrm{mM}$ after the oral intake of $10 \mathrm{mg} / \mathrm{kg}$ rebamipide in rats. ${ }^{15}$ Our experimental result that $H$ pylori enhanced $\mathrm{ChL}$ release from neutrophils was significantly suppressed by rebamipide shows that rebamipide attenuates the release of oxidants from $H$ pylori elicited neutrophils. It is not clear whether this inhibition results from an oxidant scavenging effect or from a direct action for neutrophil activation process. Yoshikawa et al reported that rebamipide can only scavenge hydroxyl radical, which is not detectable in the luminol dependent $\mathrm{ChL}$ assay

Effect of rebamipide on urease activity in vitro

Values are expressed as mean (SEM) of four findings. NS=non-significant.

\begin{tabular}{lll}
\hline & Urease activity (\% of control) & p Value \\
\hline Rebamipide & & \\
$0.1 \mathrm{mM}$ & $93.6(1.9)$ & NS \\
$0.5 \mathrm{mM}$ & $85.1(2.5)$ & $<0.01$ \\
$1.0 \mathrm{mM}$ & $78.3(0.8)$ & $<0.01$ \\
\hline
\end{tabular}


that we used. ${ }^{16}{ }^{17}$ It is also known that FMLP (f-methionyl-leucyl-phenylalanine) stimulated neutrophil dependent superoxide production was inhibited by rebamipide. ${ }^{18}$ It is, therefore, concluded that rebamipide may suppress active oxidant production through modulating the neutrophil activation process, independently of its radical scavenging properties. Accordingly, the attenuation of rebamipide on toxic oxidant release may be important in preventing gastric mucosal injury associated by $H$ pylori elicited neutrophils. This toxic mechanism is supported by our experimental evidence that gastric mucosal cell damage associated with $H$ pylori and neutrophils is significantly inhibited by rebamipide.

This study shows that rebamipide significantly inhibits urease activity as well, which implies the possibility that the ammonia concentration can be reduced in gastric mucosa infected by $H$ pylori. Although it is not certain how much $H$ pylori associated urease can be inhibited by rebamipide at the concentration found in the human stomach, ammonia has been proposed to be an important pathogen to $H$ pylori associated gastric mucosal injury. The ammonia concentration of gastric juice is reported as $3.4 \mathrm{mM}$, which is not cytotoxic. ${ }^{1920}$ This concentration of ammonia, however, has been proposed to be pathogenic in the presence of activated neutrophils because neutrophil derived hypochlorous acid can react with ammonia to produce monochloramine, which is a highly toxic molecule. We have emphasised the unique role of monochloramine in $H$ pylori induced gastric mucosal damage. ${ }^{6}$ Morishita et al have also shown the clinical efficacy of taurine (monochloramine scavenger) for patients with $H$ pylori positive gastritis. ${ }^{21}$ Although monochloramine concentration was not measured in this in vitro study and the attenuating magnitude of rebamipide on urease activity is comparatively slight $(22 \%$ at $1 \mathrm{mM})$, the synchronous inhibition of rebamipide in neutrophilic oxidative bursts and $H$ pylori derived urease activity may be advantageous for preventing $H$ pylori induced gastric mucosal damage, which is mediated by monochloramine.

The in vitro bacterial growth test shows that bacterial growth of $H$ pylori is not influenced by rebamipide at concentrations less than $1 \mathrm{mM}$. This finding suggests that oral intake of rebamipide in itself cannot clinically eradicate $H$ pylori from gastric mucosa.

In conclusion, the results of this in vitro study suggest that rebamipide may be one of the valuable antiulcer compounds that also exhibit an additional efficacy for $H$ pylori induced mucosal damage associated with the ammonia monochloramine system.
We thank Dr K Yamasaki (Otsuka Pharm) for providing the gastric epithelial cells. This work was supported by a grant-inaid for scientific research from the Ministry of Education, Science and Culture of Japan and by a grant from Keio University, School of Medicine.

1 Mooney C, Keenan J, Munster D, Wilson I, Allardyce R Bagshaw $\mathbf{P}$, et al. Neutrophil activation by Helicobacter pylori. Gut 1991; 32: 853-7.

2 Mai UEH, Perez-Perez GI, Allen JB, Wahl SM, Blaser MJ Smith PD. Surface proteins from Helicobacter pylori exhibit chemotactic activity for human leukocytes and are present in gastric mucosa. F Exp Med 1992; 175: 517-25.

3 Kozol R, Domanowski A, Jaszewski R, Czanko R, McCurdy $B$, Prasad $M$, et al. Neutrophil chemotaxis in gastric mucosa - a signal-to-response comparison. Dig Dis $\mathrm{Sc}$ 1991; 36: 1277-80.

4 Craig PM, Territo MC, Karnes WE, Walsh JH. Helicobacter pylori secretes a chemotactic factor for monocytes and neutrophils. Gut 1992; 33: 1020-3.

5 Kozol R, McCurdy B, Czanko R. A neutrophil chemotactic factor present in $\mathrm{H}$ pylori but absent in $\mathrm{H}$ mustelae. Dig Dis Sci 1993; 38: 137-41.

6 Suzuki M, Muira S, Suematsu M, Fukumura D, Kurose I, Suzuki H, et al. Helicobacter pylori-associated ammonia production enhances neutrophil-dependent gastric mucosal cell injury. Am f Physiol (Gastrointest Liver Physiol) 1992; 263: G719-25.

Suzuki M, Miura S, Suematsu M, Fukumura D, Suzuki $H$ Kai A, et al. Helicobacter pylori elicits gastric mucosal cel damage associated with neutrophil-derived toxic oxidants. Eur F Gastroenterol Hepatol 1993; 5 (Suppl 1): S35-9.

8 Ishihara K, Komuro Y, Nishiyama N, Yamasaki K, Hotta $K$. Effect of rebamipide on mucus secretion by endogenous prostaglandin-independent mechanism in rat genous prostaglandin-independent mechanism in rat

Yamasaki $\mathrm{K}$, Kanbe $\mathrm{T}$, Chijiwa $\mathrm{T}$, Ishiyama Gastric mucosal protection by OPC-12759, a nove antiulcer compound, in the rat. Eur $f$ Pharmacol 1987 142: 23-9.

10 Oka S, Ogino K, Hobara T, Yoshimura S, Okazaki Y, Takemoto $\mathrm{T}$, et al. Effects of various mucosal protective drugs on diethyldithiocarbamate-induced antral ulcer in rats. Eur F Pharmacol 1991; 197: 99-102.

11 Marshall BJ, Armstrong JA, McGechie DB, Glancy RJ Attempt to fulfil Koch's postulates for pyloric campylobacter. Med $₹$ A ust 1985; 142: 436-9.

12 Morris A, Nicholson G. Ingestion of Campylobacter pyloridis causes gastritis and raised fasting gastric $\mathrm{pH}$ Am F Gastroenterol 1987; 82: 192-9.

13 Yoshida N, Granger DN, Evans DJ Jr, Evans DG Graham DY, Anderson DC, et al. Mechanisms involved in Helicobacter pylori-induced inflammation. Gastroenterology 1993; 105: 1431-40.

14 Kurose I, Kvietys PR, Wolf R, Evans DJ, Evans DG Graham DY, et al. Mechanisms of $\mathrm{H}$ pylori-induced microvascular dysfunction. Gastroenterology 1993; 104: A728.

15 Shioya Y, Kashiyama E, Okada K, Kusumoto N, Abe Y, Uchida $M$, et al. Metabolic fate of the anti-ulce agent, $( \pm)-2-(4$-chlorobenzoylamino $)-3-[2(1 \mathrm{H})$-quinolinon-4-yl]propionic acid (OPC-12759) - absorption, distribution and excretion in rats and dogs. Iyakuhin Kenkyu 1989; 20: 522-33. (English abstract.)

16 Yoshikawa T, Naito Y, Tanigawa T, Kondo M. Free radical scavenging activity of the novel anti-ulcer agent rebamipide studied by electron spin resonance. Arzneimittelforschung 1993; 43: 363-6.

17 Suematsu M, Oshio C, Miura S, Suzuki M, Houzawa S, Tsuchiya M. Luminol-dependent photoemission from single neutrophil stimulated by phorbor ester and calcium single neutrophil stimulated by phorbor ester and calcium ionophore - role of degranulation and myeloperoxid
Biochem Biophys Res Commun 1988; 155: 106-11.

18 Ogino $\mathrm{K}$, Hobara $\mathrm{T}$, Ishiyama $\mathrm{H}$. Antiulcer mechanism of action of rebamipide, a novel antiulcer compound, on diethyldithiocarbamate-induced antral gastric ulcers in rats. Eur F Pharmacol 1992; 212: 9-13.

19 Neithercut WD, Milne A, Chittajallu RS, el Nujumi AM McColl KE. Detection of Helicobacter pylori infection of the gastric mucosa by measurement of gastric aspirate ammonium and urea concentrations. Gut 1991; 32: 973-6.

20 Tsujii M, Kawano S, Tsujii S, Fusamoto H, Kamada T, Sato N. Mechanism of gastric mucosal damage induced by ammonia. Gastroenterology 1992;102: 1881-8.

21 Morishita T, Muto A, Shiozaki H, Nagahama T, Eimoto A Sawaguchi $\mathrm{K}$, et al. Efficacy of taurine in the treatment of gastric mucosal lesions associated with Helicobacte pylori. Eur $\mathcal{f}$ Gastroenterol Hepatol 1993; 5 (suppl 1) S133-6. 